\title{
The Effect of Combined Aerobic and Resistance Exercise Training on Abdominal Fat in Obese Middle-aged Women
}

\author{
Sang-Kab Park ${ }^{1)}$, Jae-Hyun Park ${ }^{1)}$, Yoo-Chan Kwon'), Ho-Sung Kim ${ }^{1)}$, \\ Mi-Suk Yoon ${ }^{1)}$ and Hyun-Tae Park ${ }^{2)}$ \\ 1) Department of Physical education, College of Physical education, Dong-A University, Korea \\ 2) Department of Physical and health education University of Tokyo
}

\begin{abstract}
The purpose of this study was to investigate the effect of combined aerobic and resistance training on abdominal fat. Our participants in the study consisted of thirty obese women. They were separated into three groups: a control group $(\mathrm{n}=10)$, an aerobic training group $(\mathrm{n}=10)$ and a combined training group $(\mathrm{n}=10)$. The aerobic training group was composed of $60-70 \%$ HRmax (intensity), 60 minutes a day (duration) for 6 days a week (frequency). The combined training group was separated into resistance training (3 days a week, Mon, Wed, Fri) and the aerobic training (3 days a week, Tue, Thu, Sat). The levels for abdominal fat volume were measured by determining the subcutaneous fat volume (SFV), visceral fat volume (VFV), and VFV/SFV by CT (computed tomography). The $\dot{\mathrm{VO}}_{2 \max }$ was significantly $(\mathrm{p}<0.05)$ increased in both groups. The subcutaneous fat and visceral fat levels were decreased in the combined training group more than in the aerobics training group. Also, the lean body mass (LBM) was significantly increased only in the combined training group. In addition, the total cholesterol, triglyceride and LDL$\mathrm{C}$ were significantly $(\mathrm{p}<.05)$ decreased and the HDL-C was significantly $(\mathrm{p}<.05)$ increased in both groups. In conclusion, our results observed that combined training decreased abdominal subcutaneous fat and visceral fat more than aerobic training only. J Physiol Anthropol 22 (3): 129-135, 2003 http://www.jstage.jst.go.jp/en/
\end{abstract}

Keywords: aerobic training, resistance training, combined training, subcutaneous fat, visceral fat

\section{Introduction}

The lack of physical activity in daily life induces obesity and increases the risk of hypokinetic diseases; diabetes mellitus, hypertension, heart diseases etc. The major cause for the risk of hypokinetic diseases is obesity. Since various types of diseases are induced by obesity rather than the serious aspect of obesity alone, they become an issue as well (Leutholtz et al., 1995).

Obesity is classified into symptomatic obesity, which is caused by different diseases and simple obesity that is caused by the surplus accumulation of fat inside the body. Although there are various causes of simple obesity, genetic and physical constitutional factors, the dietetic factor of excessive calories, and the decrease of activity or lack of exercise, become the major factors in the cause of obesity. Therefore, except for the genetic factor, the imbalance between intake calories and consumption calories can be thought of as the major cause of obesity. In balancing energy, the lack of physical activity contributes to the major factor of obesity. Moreover, treating obesity is extremely important because if not addressed the risk of cardiovascular diseases and the loss of self-confidence increases. It also degrades the ability of exercise performance as well as mental, emotional and social interaction. As a rule, obesity is a main risk factor for a number of diseases. The etiology of obesity is unclear, although it appears that both genetic and environmental factors contribute to its development (Hanley et al., 1997).

In recently published studies reported, abdominal fat accumulation is one of the risk factors of coronary heart disease. Visceral fat was reported to promote secretion of free fat acid and decrease the insulin receptor sensitivity (Reaven, 1988). Also, if amounts of abdominal fat accumulate, blood sugar, insulin secretion and serum triglyceride concentrations increase, so morbidity of diabetes mellitus, ischemic heart disease and apoplexy may appear. Poehlman and Horton (1989) reported that aerobic training increases energy expenditure by activation of lipolysis. Therefore, aerobic training affects the reduction of weight and body fat, whereas resistance training affects the maintenance or increase in LBM (Ballor et al., 1988). Combined aerobic and resistance training is the best program to treat obesity (Hill et al., 1987).

Obesity is related to the occurrence of life-style related diseases. Accurate diagnosis of obesity is important to health 
maintenance. In particular, the accumulation of abdominal fat is relatively high compared to other diseases (Bjorntorp et al., 1988). Obesity is improved by aerobic exercise training, but it is important to consider exercise type, intensity, and frequency. Therefore, we hypothesized that combined aerobic and resistance exercise training have an influence on abdominal subcutaneous fat, visceral fat and blood lipids.

\section{Methods}

\section{Subjects}

Subjects were thirty middle-aged obese women, aged 40-45 yrs, apparently healthy and free of regular medication. Subjects were separated into a control group $(n=10)$, aerobic training group $(n=10)$ and a combined training group $(n=10)$. Physical characteristics of subjects are shown in Table 1.

\section{Body composition measurement}

Height and weight were assessed by STDK-AD(Shintokyo Denshikizai Co.), autobody weight (YK-150N) respectively. Body mass index (BMI) was calculated as weight $(\mathrm{kg}) /$ height $\left(\mathrm{m}^{2}\right)$. \%body fat, lean body mass (LBM) were measured by Inbody 3.0 (Biospace, Korea). Blood pressure at rest was obtained from the right arm by auscultation using a mercury sphygmomanometer.

\section{Maximal exercise test}

Exercise capacity was measured both at the start and the end of the training program. All participants were familiar with the exercise testing protocol by having a preliminary exercise test with respiratory gas exchange measurement done one to three days before the baseline exercise test. All participants performed a maximum treadmill exercise test according to the modified Bruce protocol. The exercise test was maximized, and indication for stopping was as recommended by the American College of Sports Medicine (2000). A complete 12-lead electrocardiogram was used to monitor the participants continuously. Participants breathed through a mask with a turbine volume transducer, which measured the volume of inspired and expired air. Respired gases were withdrawn from the mask for determination of $\mathrm{O}_{2}$ and $\mathrm{CO}_{2}$ and were analyzed breath by breath (Quinton Metabolic Cart 4500 U.S.A). The gas analyzers as well as the volume transducer were calibrated before each test.

\section{Training program}

Each of the sessions was composed of 10 minutes warm-up and cool-down respectively. The aerobic training was performed 60 minutes a day, 6 days a week at $60-70 \%$ of HRmax during 1-12 weeks (side by side, step touch, lunge side, v-step, grapevine, pivot turn, cha cha cha, mambo rock, diamond step, single hamstring walking, heel touch, sit-up, push up) and at 60-70\% of HRmax during 13-24 weeks (fast walking, turn round, heel side, knee-up, scissors double, hop and jump, jumping jack, side kick, full turn, double kick). The 1 repetition maximum (RM) was measured by Kuramoto and Payne (1995) lawfulness [1 RM $=(1.06 \times$ lifted weight $(\mathrm{kg})+$ $(0.58 \times$ repetition frequency $)-(0.20 \times$ age $)-3.41)]$. Resistance training was performed 60 minutes a day at $60 \%$ of $1 \mathrm{RM}$ during 1-12 weeks and at 70\% of 1RM during 13-24 weeks (table 2). The combined training group was separated by resistance training (3 days a week, Mon, Wed, Fri) and aerobic

Table 1 The physical characteristics of subjects

\begin{tabular}{lrrr}
\hline \multicolumn{1}{c}{ Variable } & \multicolumn{1}{c}{ Control } & Aerobic training & Combined training \\
\hline Age $(\mathrm{yrs})$ & $43.1 \pm 1.67$ & $42.2 \pm 1.91$ & $43.4 \pm 1.04$ \\
Height $(\mathrm{cm})$ & $159.8 \pm 1.48$ & $158.6 \pm 3.06$ & $161.8 \pm 3.55$ \\
Body weight $(\mathrm{kg})$ & $65.2 \pm 1.87$ & $63.7 \pm 3.58$ & $67.5 \pm 5.10$ \\
Body mass index $\left(\mathrm{kg} / \mathrm{m}^{2}\right)$ & $25.5 \pm 0.86$ & $25.3 \pm 1.74$ & $25.8 \pm 1.43$ \\
Systolic blood pressure $(\mathrm{mmHg})$ & $137.7 \pm 3.23$ & $136.7 \pm 9.25$ & $138.5 \pm 4.11$ \\
Diastolic blood pressure $(\mathrm{mmHg})$ & $83.5 \pm 10.83$ & $88.1 \pm 2.46$ & $86.5 \pm 4.11$ \\
\hline
\end{tabular}

Table 2 The resistance training intensity

\begin{tabular}{lccc}
\hline & $1 \mathrm{RM}$ & $60 \%(1-12$ weeks $)$ & $70 \%(13-24$ weeks $)$ \\
\hline Bench press (kg) & $23.5 \pm 5.30$ & $14.1 \pm 3.18$ & $16.4 \pm 3.58$ \\
Side raise (kg) & $10.2 \pm 2.20$ & $6.1 \pm 1.32$ & $7.1 \pm 1.54$ \\
Triceps push away (kg) & $12.2 \pm 3.09$ & $7.2 \pm 1.85$ & $8.4 \pm 2.16$ \\
Barbell curl (kg) & $15.3 \pm 2.75$ & $9.1 \pm 1.67$ & $10.4 \pm 2.10$ \\
Leg curl (kg) & $22.0 \pm 4.83$ & $13.1 \pm 3.00$ & $15.4 \pm 3.38$ \\
Leg extension (kg) & $54.0 \pm 9.37$ & $32.4 \pm 5.62$ & $37.8 \pm 6.56$ \\
Leg press (kg) & $142.0 \pm 33.93$ & $85.2 \pm 20.36$ & $99.4 \pm 23.75$ \\
Leg raise (kg) & $24.1 \pm 13.03$ & $14.5 \pm 7.82$ & $16.8 \pm 9.11$ \\
Abdominal crunch $(\mathrm{kg})$ & $19.3 \pm 5.60$ & $11.6 \pm 3.36$ & $13.5 \pm 3.92$ \\
Lat pull down (kg) & $36.5 \pm 5.30$ & $21.9 \pm 3.18$ & $25.6 \pm 3.71$ \\
\hline
\end{tabular}

RM : Repetition Maximum 
Table 3 The comparison of maximal oxygen consumption $\left(\dot{\mathrm{V}}_{2 \max }\right)$ between baseline and 24 weeks

\begin{tabular}{|c|c|c|c|c|c|}
\hline Variable & Group & Baseline & 24 weeks & diff & t-value \\
\hline \multirow[t]{4}{*}{$\mathrm{VO}_{2 \max }(\mathrm{ml} / \mathrm{min})$} & Control & $2134.1 \pm 344.0$ & $1979.9 \pm 135.0$ & -154.2 & 1.56 \\
\hline & Aerobics & $2226.2 \pm 230.9$ & $2547.3 \pm 223.1$ & 321.1 & $4.67 * *$ \\
\hline & Combined & $2239.4 \pm 325.1$ & $2604.7 \pm 286.8$ & 365.3 & $4.96^{* *}$ \\
\hline & F-value & 0.356 & $23.486^{\dagger \dagger}$ & & \\
\hline \multirow[t]{4}{*}{$\mathrm{VO}_{2 \max }(\mathrm{ml} / \mathrm{kg} / \mathrm{min})$} & Control & $30.9 \pm 3.6$ & $30.3 \pm 2.5$ & -0.6 & 0.84 \\
\hline & Aerobics & $34.2 \pm 3.2$ & $43.1 \pm 3.9$ & 8.9 & $6.85^{* *}$ \\
\hline & Combined & $32.1 \pm 4.7$ & $42.3 \pm 6.8$ & 10.2 & $7.03 * *$ \\
\hline & F-value & 1.749 & $22.834^{\dagger \dagger}$ & & \\
\hline \multirow[t]{4}{*}{$\mathrm{VO}_{2} / \mathrm{LBM}(\mathrm{ml} / \mathrm{kg} / \mathrm{min})$} & Control & $52.2 \pm 8.3$ & $50.1 \pm 4.7$ & -2.1 & 0.99 \\
\hline & Aerobics & $60.9 \pm 6.7$ & $63.6 \pm 5.2$ & 2.7 & 0.55 \\
\hline & Combined & $56.6 \pm 6.9$ & $62.4 \pm 8.7$ & 5.8 & $2.74 *$ \\
\hline & F-value & 3.532 & $12.504^{\dagger \dagger}$ & & \\
\hline
\end{tabular}

LBM : lean body mass,

Significantly different from baseline : $* \mathrm{p}<0.05,{ }^{* *} \mathrm{p}<0.01$

Significance difference among groups : ${ }^{\dagger} \mathrm{p}<0.05,{ }^{\dagger \dagger} \mathrm{p}<0.01$

training (3 days a week, Tue, Thu, Sat). Polar Analyzer (Polar Elector oy Finland) was used to continuously to maintain $60 \%$ to $70 \%$ of heart rate reserve during the aerobic exercise training program.

\section{Computed tomography}

In each subject the computed tomogram was taken immediately cranial to the iliac and was chosen for further analysis. Such a level usually traverses the body of the fourth lumbar vertebra and is close to the umbilicus in most subjects. By means of describing regions of interest (ROI) with a light pen cursor and assessing the number of pixels within the fat density range ( -250 to -50 Hounsfield number) the cross sectional areas of both visceral fat and subcutaneous fat were calculated

\section{Blood sample analysis}

Blood was drawn from the antecubital vein at baseline and 24 weeks. After the subject fasted for a minimum of 12 hours, blood samples of approximately $10 \mathrm{ml}$ were collected in the early morning by venipuncture from the antecubital vein. The samples were then centrifuged to obtain the serum, which was stored at $4^{\circ} \mathrm{C}$. All analyses were completed within 48 hours of the collection of the blood samples. The concentrations of both total choesterol (TC) and triglyceride (TG) in the serum were measured using enzymatic assays (DAOS, Wako Shiyaku). The high density lipoprotein-cholesterol (HDL-C) in the serum was measured by heparin-manganese precipitation procedure (DAOS, Kyowa Medics). The low density lipoproteincholesterol (LDL-C) was calculated according to the method of Friedewald et al. (1972) which assumes that LDL-C $=$ TC(HDL-C+TG/5). Apolipoportein A-I and Apolipoportein B were measured by single radial immunodiffusion.

\section{Statistical analysis}

All data are presented as means \pm SD. Paired t-test was used to evaluate the difference of baseline and 24 weeks. And oneway ANOVA was used to evaluate change among groups, if $\mathrm{F}$ value was significant, it was determined using Scheffe's test. All analyses were done with SPSS statistical software (SPSS Korea). Statistical significance was accepted at $\mathrm{p}<0.05$.

\section{Results}

\section{Maximal oxygen consumption $\left(\vec{V} O_{2 \max }\right)$}

Table 3 shows the data of maximal oxygen consumption on subjects who participated in this study. There were no significant differences among 3 groups at baseline. $\dot{\mathrm{VO}}_{2 \max }$, $\dot{\mathrm{V}}{ }_{2 \max } / \mathrm{kg}$ were significantly $(\mathrm{p}<0.01)$ increased in both aerobic training and the combined training group. However $\dot{\mathrm{V}} \mathrm{O}_{2 \max } / \mathrm{LBM}$ was significantly $(\mathrm{p}<0.05)$ increased in only the combined training group.

\section{Body composition}

The comparison of body composition between baseline and 24 weeks are presented in Table 4. Body weight, SFV, VFV, $\mathrm{VFV} / \mathrm{SFV}$ were increased, and LBM was decreased. But there was no significance. On the other hand, percent fat was significantly increased after 24 weeks in the control group. Weight and \%body fat were significantly decreased respectively in both training groups compared to control group. LBM was not different in the aerobic training group. However, combined training was increased $(p<0.05)$. SFV was decreased in aerobic $(\mathrm{p}<0.05)$ and combined training $(\mathrm{p}<0.01)$, VFV was decreased in aerobic and combined training group and VFV/SFV was decreased in both training groups $(\mathrm{p}<0.01)$. In particular, SFV and VFV were decreased in the combined training group rather than the aerobic training group. LMB was significantly increased only in the combined 
Table 4 The comparison of body composition between baseline and 24 weeks

\begin{tabular}{|c|c|c|c|c|c|}
\hline Variable & Group & Baseline & 24 weeks & diff & t-value \\
\hline \multirow[t]{4}{*}{ Body weight (kg) } & Control & $65.2 \pm 1.87$ & $65.8 \pm 1.32$ & 0.6 & 1.500 \\
\hline & Aerobics & $63.7 \pm 3.58$ & $59.0 \pm 3.02$ & -4.7 & $5.662 * *$ \\
\hline & Combined & $67.5 \pm 5.10$ & $61.1 \pm 4.16$ & -6.4 & $5.150 * *$ \\
\hline & F-value & 2.605 & $4.054^{\dagger}$ & & \\
\hline \multirow[t]{4}{*}{ Body fat $(\%)$} & Control & $40.3 \pm 2.08$ & $42.6 \pm 2.08$ & 2.3 & $3.246^{*}$ \\
\hline & Aerobics & $42.2 \pm 1.49$ & $33.0 \pm 4.49$ & -9.2 & $6.734 * *$ \\
\hline & Combined & $41.4 \pm 4.54$ & $31.1 \pm 4.44$ & -10.3 & $6.290 * *$ \\
\hline & F-value & 0.203 & $16.570^{\dagger \dagger}$ & & \\
\hline \multirow[t]{4}{*}{ Lean body mass (kg) } & Control & $38.1 \pm 3.17$ & $37.7 \pm 1.64$ & -0.4 & 1.575 \\
\hline & Aerobics & $37.5 \pm 4.18$ & $38.4 \pm 3.23$ & 0.9 & 1.706 \\
\hline & Combined & $37.4 \pm 3.62$ & $43.0 \pm 6.44$ & 5.6 & $2.607 *$ \\
\hline & F-value & 1.002 & 1.895 & & \\
\hline \multirow{4}{*}{$\begin{array}{l}\text { Abdominal subcutaneous fat } \\
\text { volume }\left(\mathrm{cm}^{3}\right)\end{array}$} & Control & $595.1 \pm 77.83$ & $598.4 \pm 68.95$ & 3.3 & 1.251 \\
\hline & Aerobics & $602.0 \pm 67.31$ & $578.9 \pm 73.76$ & -23.1 & $3.047 *$ \\
\hline & Combined & $646.0 \pm 91.33$ & $584.2 \pm 75.55$ & -61.8 & $6.669 * *$ \\
\hline & F-value & 2.191 & 0.192 & & \\
\hline \multirow{4}{*}{$\begin{array}{l}\text { Abdominal visceral fat } \\
\text { volume }\left(\mathrm{cm}^{3}\right)\end{array}$} & Control & $182.9 \pm 16.81$ & $190.4 \pm 15.74$ & 7.5 & 0.048 \\
\hline & Aerobics & $195.0 \pm 12.55$ & $112.4 \pm 10.50$ & -82.6 & $20.883^{* *}$ \\
\hline & Combined & $201.6 \pm 28.03$ & $108.6 \pm 17.85$ & -93.0 & $23.070 * *$ \\
\hline & F-value & 1.207 & $94.410^{\dagger \dagger}$ & & \\
\hline \multirow[t]{4}{*}{ Visceral fat/subcutaneous fat } & Control & $0.31 \pm 0.07$ & $0.32 \pm 0.02$ & 0.01 & 0.499 \\
\hline & Aerobics & $0.33 \pm 0.02$ & $0.20 \pm 0.02$ & -0.13 & $8.827 * *$ \\
\hline & Combined & $0.31 \pm 0.02$ & $0.19 \pm 0.02$ & -0.12 & $6.669^{* *}$ \\
\hline & F-value & 0.250 & $146.236^{\dagger \dagger}$ & & \\
\hline
\end{tabular}

Significantly different from baseline : $* \mathrm{p}<0.05, * * \mathrm{p}<0.01$

Significance difference among groups : ${ }^{\dagger} \mathrm{p}<0.05,{ }^{\dagger \dagger} \mathrm{p}<0.01$

training group. Therefore, combined training was more effective on body composition.

\section{Serum lipids and lipoproteins}

The change in serum lipids and lipoproteins after 24 weeks were presented in Table 5. Serum lipids and lipoproteins were little changed after 24 weeks in the control group. TC, LDL-C, TG were significantly $(\mathrm{p}<0.01)$ decreased and HDL-C was significantly $(\mathrm{p}<0.01)$ increased in both training groups. Apo A-I was significantly $(\mathrm{p}<0.01)$ increased and Apo B was significantly $(p<0.01)$ decreased in aerobics and combined training group. Degree of variation was high in combined training group compared to the aerobics training group. However, statistical difference appeared in both training groups.

\section{Discussion}

Aerobic capacity $\left(\dot{\mathrm{VO}}_{2 \max }\right)$ is due primarily to heredity and training, generally the ratio is 50\% (Fagard and Bielen, 1991; Engstr and Fischbein, 1997). In the present study, $\dot{\mathrm{VO}}_{2 \max }$ was decreased in the control group but increased in the aerobics training group and the combined training group (aerobics plus resistance training). In the case of the $\dot{\mathrm{VO}}_{2 \max }$ per kilogram of body weight, combined training group showed more increase than in the others. Therefore, the combined training group is more effective than other groups.

In general, the training has a positive effect on body composition. Also, it is reported that resistance training increases LBM and aerobic training decreases body fat. Eric et al. (2000) reported that resistance training ( $80 \%$ of $1 \mathrm{RM}, 3$ times/week, 6 months, $30 \mathrm{yr}$ women) increased in LBM but not in body fat. Owens et al (1999) reported that aerobic training ( 157 beat $/ \mathrm{min}, 40 \mathrm{~min} / \mathrm{set}$, 5 times/week, 4 months in obese adolescents) decreased body fat by $22 \%$.

In our study, the aerobics training group significantly decreased in body weight $(4.7 \mathrm{~kg}), \%$ body fat $(9.2 \%)$ but not in LBM. The combined training group also decreased in body weight $(6.4 \mathrm{~kg})$ and \%body fat $(10.3 \%)$, but especially increased in LBM $(5.6 \mathrm{~kg}, \mathrm{p}<0.05)$. Therefore, combined training is more effective in improving body composition.

The level of LBM in women with abdominal obesity is associated with GnHR (gonadotropin-releasing hormone), GH (growth hormone), dyinsulinemia and estrogen deficiency (Yamasaki et al., 2001). It is assumed that combined training could decrease body fat and increase LBM in middle-aged 
Table 5 The comparison of serum lipids and lipoproteins between baseline and 24 weeks

\begin{tabular}{|c|c|c|c|c|c|}
\hline Variable & Group & Baseline & 24 weeks & diff & $\mathrm{t}$-value \\
\hline \multirow[t]{4}{*}{ Total-cholesterol (mg/dl) } & Control & $235.6 \pm 13.35$ & $240.3 \pm 11.52$ & 4.7 & 1.52 \\
\hline & Aerobics & $232.4 \pm 21.40$ & $187.0 \pm 23.02$ & -45.4 & $5.69^{* *}$ \\
\hline & Combined & $247.5 \pm 24.36$ & $184.5 \pm 21.88$ & -63.0 & $5.58 * *$ \\
\hline & F-value & 1.239 & $17.885^{\dagger \dagger}$ & & \\
\hline \multirow[t]{4}{*}{ Low density lipoprotein-C (mg/dl) } & Control & $160.6 \pm 29.43$ & $149.7 \pm 14.82$ & -10.9 & 1.42 \\
\hline & Aerobics & $157.7 \pm 20.13$ & $112.9 \pm 21.25$ & -44.8 & $5.74 * *$ \\
\hline & Combined & $175.4 \pm 21.49$ & $114.6 \pm 22.66$ & -60.8 & $5.99 * *$ \\
\hline & F-value & 1.553 & $26.695^{\dagger \dagger}$ & & \\
\hline \multirow[t]{4}{*}{ High density lipoprotein-C (mg/dl) } & Control & $45.2 \pm 4.04$ & $44.1 \pm 2.42$ & -1.1 & 0.88 \\
\hline & Aerobics & $46.2 \pm 2.57$ & $55.4 \pm 3.62$ & 9.2 & $6.61 * *$ \\
\hline & Combined & $42.4 \pm 6.81$ & $52.2 \pm 4.39$ & 9.8 & $5.49^{* *}$ \\
\hline & F-value & 1.689 & $10.937^{\dagger \dagger}$ & & \\
\hline \multirow[t]{4}{*}{ Triglyceride (mg/dl) } & Control & $173.1 \pm 23.01$ & $181.8 \pm 27.59$ & 8.7 & 0.27 \\
\hline & Aerobics & $145.7 \pm 15.07$ & $101.0 \pm 16.68$ & -44.7 & $5.99^{* *}$ \\
\hline & Combined & $148.8 \pm 5.82$ & $85.8 \pm 5.03$ & -63.0 & $5.47 * *$ \\
\hline & F-value & 0.585 & $12.631^{\dagger \dagger}$ & & \\
\hline \multirow[t]{4}{*}{ Apolipoprotein A-I (mg/dl) } & Control & $133.9 \pm 23.68$ & $124.1 \pm 11.33$ & -9.8 & 1.33 \\
\hline & Aerobics & $136.1 \pm 11.89$ & $157.1 \pm 27.59$ & 21.0 & $2.36^{*}$ \\
\hline & Combined & 132.0610 .17 & $163.5 \pm 23.23$ & 31.5 & $4.43 * *$ \\
\hline & F-value & 0.157 & $9.384^{\dagger \dagger}$ & & \\
\hline \multirow[t]{4}{*}{ Apolipoprotein B (mg/dl) } & Control & $151.0 \pm 31.21$ & $167.7 \pm 31.22$ & 16.7 & 1.55 \\
\hline & Aerobics & $166.7 \pm 18.70$ & $138.9 \pm 19.36$ & -27.8 & $2.89^{*}$ \\
\hline & Combined & $154.5 \pm 27.20$ & $124.9 \pm 21.18$ & -29.6 & $2.64 *$ \\
\hline & F-value & 0.987 & $7.931^{\dagger \dagger}$ & & \\
\hline
\end{tabular}

Significantly different from baseline: $* \mathrm{p}<0.05, * * \mathrm{p}<0.01$

Significance difference among groups : ${ }^{\dagger} \mathrm{p}<0.05,{ }^{\dagger \dagger} \mathrm{p}<0.01$

obese women, which would result in an improvement of GH, dyinsulinemia.

Recently, Park (2001) reported that combined training (aerobic training plus muscular resistance training) decreased intra-abdominal fat. Combined training is more effective in reducing visceral fat than food intake restriction. But, Despres et al. (1991) reported that 14 weeks of aerobic training decreased abdominal subcutaneous fat $\left(546.5 \pm 128.2 \mathrm{~cm}^{3}\right.$ into $\left.486.5 \pm 123.3 \mathrm{~cm}^{3}\right)$ whereas it did not reduce visceral fat $\left(124.7 \pm 48.6 \mathrm{~cm}^{3}\right.$ into $\left.121.3 \pm 45.5 \mathrm{~cm}^{3}\right)$. Mourier et al. (1997) showed that cycle ergometer exercise $\left(75 \%\right.$ of $\dot{\mathrm{VO}}_{2 \text { peak }}$, $45 \mathrm{~min} / \mathrm{set}$, twice a week, 8 weeks long) in subjects with type 2 diabetes decreased the abdominal subcutaneous fat $(18 \%)$ and visceral fat $(48 \%)$.

The effects of the decreased visceral fat demonstrated that activated-lipolysis played a more important role in visceral fat than subcutaneous fat through the catecholamine stimulation. Shimomura et al. (1993) observed a marked reduction of acylCoA synthase activity (67\% to sedentary group/tissue protein) and acyl-CoA synthase mRNA ( $26 \%$ to sedentary group), combined with reduction of LPL mRNA (49\%) and GLUT-4 mRNA $(38 \%)$ in the visceral fat of exercised rats through 7day training. Visceral fat is activated in lipolysis by catecholamine stimulation during exercise because the probability is that visceral fat will be mobilized.

In our study, visceral fat decreased more than subcutaneous fat in both training groups. But the combined training group experienced a greater decrease of visceral fat more than the aerobics training group did. Although, we did not analyze catecholamine, our result agreed with the results of the Shimomura et al. (1993). Therefore, we suggest that combined training is more likely to activate lipolysis than by catecholamine stimulation.

If the ratio of the subcutaneous and visceral fat is 0.4 , which is the index of the abdominal obese, it is considered to be the abdominal obese. The abdominal obesity with the ratio higher than 0.4 was highly related to the circulation and endocrine system. Whereas, both aerobics training and combined training was significantly reduced from 0.33 to 0.20 and from 0.31 to 0.19 after 24 weeks. According to the result of the experiment, both subcutaneous and visceral fat significantly decreased. Therefore, the combined training will benefit the increase of the lean body mass of middle-aged obese females. It is also effective in decreasing the abdominal subcutaneous and visceral fat. Moreover, it will help prevent all kinds of diseases caused by obesity. 
Lamarche et al. (1992) performed the experiment on the training, for both weight rising group and weight reducing group, using approximately $55 \%$ of maximal aerobic power with four to five times a week for a period of 6 months. The experimenter observed the improvement in the sugar, and lipid metabolism in both groups. Krotkiewski and Bjorntorp (1986) reported that insulin sensitivity, TG and cholesterol were improved after 3 months on the training for abdominal obesity patients. Fahlman et al. (2002) performed the experiment on aerobic training group ( $70 \%$ of HRR) and resistance training group ( $8 \mathrm{RM}$ ) with 50 minutes, three times a week, for a period of 10 weeks in elderly women. There were decreases in $\mathrm{TG}$, LDL-C and an increase in HDL-C in both groups.

Warner et al. (1989) reported that Apo B was significantly decreased after 12 weeks. He suggested that aerobic training needed 4-12 weeks to change blood lipid and lipoprotein concentrations. David et al. (2000) performed the experiment on the aerobic training, using $60-80 \%$ of $\mathrm{VO}_{2}$ peak with $30-60$ minutes, for a period of 12-16 weeks. The experimenter observed that Apo B was decreased and Apo A-I was increased. Furthermore, Park et al. (2001) reported that TC, TG, LDL-C, Apo B were significantly decreased and HDL-C, Apo A-I increased through combined training.

In our study, TC, TG, LDL-C and Apo B were significantly decreased and HDL-C and Apo A-I were significantly increased in both groups. This result agrees with the results of the previous experiments (Fahlman, 2002: Park, 2001). Therefore, regular long-term training is considered to improve serum lipid.

In summary, we observed that subcutaneous fat and visceral fat were decreased by combined training rather than only by aerobic training. Moreover, 24 weeks training will benefit the treatment of obesity as well as prevention of life style related diseases, due to changes in body composition, serum lipid and abdominal fat.

\section{Reference}

A.C.S.M. (2000) Guidelines for exercise testing and prescription. Baltimore. Williams \& Wilkins 117

Ballor DL, Katch VL, Becque MD, Marks CR (1988) Resistance weight training during caloric restriction enhances lean body weight maintenance. Am J Clin Nutr 47(1): 19-25

Bjorntorp P, Bouchard C, Callaway W, Kissebah A, Kral JG, Smith U (1988) Note on nomencalture. Acta Med Scand 723 (suppl): 237

David EL, Mustafa A, Leo KN, Juha M, Chandan KS, Timo AL, Mattii JU (2000) Aerobic exercise and the lipid profile in type 1 diabetic men: a randomized controlled trial. Med Sci Sports Exerc 32: 1541-1548

Despres JP, Pouliot MC, Moorjani S (1991) Loss of abdominal fat and metabolic response to exercise training in obese women. Am J Physiol 261: E159-E167

Engstr OM, Fischbein S (1997) Physical capacity in twins. Act
Genet Med Gemellol 26: 159-165

Eric TP, Roman VD, Walter FD, Martin B, Philip AA (2000) Effects of resistance training and endurance training on insulin sensitivity in nonobese, young women: a controlled randomized trial. J Clin Endocrinol Metab 85: 2463-2468

Fagard REB, Amery A (1991) Heritability of aerobic power and anaerobic energy generation during exercise. J Appl Physiol 70: 357-362

Fahlman MM, Boardley D, Lambert CP, Flynn MG (2002) Effects of endurance training and resistance training on plasma lipoprotein profiles in elderly women. J Gerontol A Biol Sci Med Sci 57: B54-60

Friedewald WT, Levy RI, Fredrickson DS (1972) Estimation of the concentration of low-density lipoprotein cholesterol in plasma, without use of the preparative ultracentrifuge. Clin Chem 18: 499-502

Hanley AG, Kwan J, Harris SB, Zinman B, Gao XJ (1997) Serum immunoreactive leptin concentrations in a Canadian Aboriginal population with rate of NIDDM. Diabetes Care 20: $1408-1415$

Hill JO, Sparling PB, Shields TW, Heller PA (1987) Effect of exercise and food restriction on body composition and metabolic rate in obese women. Am J Clin Nutr 46: 622-630

Krotkiewski M, Bjorntorp P (1986) Muscle tissue in obesity with different distribution of adipose tissue. Effects of physical training. Int J Obes 10: 331-341

Kuramoto AK, Payne VG (1995) Predicting muscular strength in women: A preliminary study. Res Q Exerc Sport 66: 168172

Lamarche B, Despres JP, Pouliot MC, Moorjani S, Lupien PJ, Theriault G, Tremblay A, Nadeau A, Bouchard C (1992) Is body fat loss a determinant factor in the improvement of carbohydrate and lipid metabolism following aerobic exercise training in obese women? Metabolism 41: 12491256

Leutholtz BC, Keyser RE, Heusner WW, Wendt VE, Rosen L (1995) Exercise training and severe caloric restriction: Effect on lean body mass in the obesity. Arch Phys Med Rehabil 76(1): 65-70

Mourier A, Gautier JF, De Kerviler E (1997) Mobilization of visceral adipose tissue related to the improvement in insulin sensitivity in response to physical training in NIDDM. Effects of branched chain amino acid supplements. Diabetes Care 20: 385-391

Owens S, Gutin B, ALllison J, Riggs S, Ferguson M, Litaker M, Thompson W (1999) Effect of physical training on total and visceral fat in obese children. Med Sci Sports Exerc 31: $143-148$

Park SK (2001) The effect of muscular resistance and aerobic training on abdominal fat. Kor Soc Spo Med 19: 275-291

Poehlman ET, Horton ES (1989) The impact of food intake and exercise on energy expenditure. Nutr Rev 47: 129-137

Reaven GM (1988) Role of insulin resistance in human disease. Diabetes 37: 1959-1607 
Shimomura I, Tokunaga K, Kotani K (1993) Marked reduction of acyl-Co A synthetase activity and mRNA intra-abdominal visceral fat by physical exercise. Am J Physiol 265: E44E50

Warner JG, Ullrich IH, Albrink MJ, Yeater RA (1989) Combined effects of aerobic exercise and omega- 3 fatty acids in hyperlipidemic persons. Med Sci Sports Exe 21(5): 498-505

Yamasaki H, Douchi T, Yamamoto S, Oki T, Kuwahata R, Nagata Y (2001) Body fat distribution and body composition during GnRH agonist therapy. Obstet Gynecol 97: $338-342$

Received: October 4, 2002

Accepted: January 31, 2003

Correspondence to: Sang-Kab Park, Department of Physical education, College of Physical education, Dong-A University, Korea

e-mail:sgpark@donga.ac.kr 